\title{
Enhancement of Hydrocarbons Degradation by Use of Pseudomonas Biosurfactants and Biofilms
}

\author{
Amina Meliani ${ }^{1 *}$ and Ahmed Bensoltane ${ }^{2}$ \\ ${ }^{1}$ Laboratory of Research of Biological Systems and Geomatic, Department of Biology, Faculty of Science, University Mascara, 29000, Mascara, Algeria \\ ${ }^{2}$ Laboratory of Food and Industrial microbiology, Department of Biology, Faculty of Science, University Oran (Es-senia), 31000 Oran, Algeria
}

"Corresponding author: Amina Meliani, Laboratory of Research of Biological Systems and Geomatic, Department of Biology, Faculty of Science, University Mascara, 29000, Mascara, Algeria, Tel: E-mail: ameliani2003@yahoo.fr

Rec date: Feb 24, 2014, Acc date: Mar 27, 2014, Pub date: Apr 05, 2014

Copyright: (c) 2014 Meliani A, et al. This is an open-access article distributed under the terms of the Creative Commons Attribution License, which permits unrestricted use, distribution, and reproduction in any medium, provided the original author and source are credited.

\begin{abstract}
Biofilm-mediated bioremediation presents a proficient alternative to bioremediation with planktonic microorganisms and are generally associated with microbial hydrocarbons resistance or tolerance. Here we report on the ability of three species of Pseudomonas biofilm-associated cells ( $P$. fluorescens, $P$. putida and $P$. aeruginosa) to degrade gasoline (hydrocarbon mixtures), xylene and benzene (monoaromatic compounds) and cyclohexane (cyclic compounds). Changes in biofilm formation and siderophores production were monitored in the presence of different concentrations of benzene and xylene. All strains were able to synthesize biosurfactant compounds and were able to tolerate aromatic hydrocarbon more than the cyclic compounds. Our results indicated that hydrocarbon mixture or gasoline could be better biodegraded by bacterial consortia; $P$. aeruginosa exhibited the best tolerance to gasoline but not to benzene and cyclohexane. It is interesting to point out that $P$. fluorescens was able to use xylene and benzene even though $P$. putida was incapable to grow on benzene as a carbon source. Statistically no significant positive correlation $(r=0.94 ; p>0.01)$ between biofilm formation and surface tension, whereas with E24 and cells hydrophobicity we signaled a linear negative relationship $(r=-93, r=-086)$.
\end{abstract}

This study is essential since Pseudomonas biofilms are found to have implication in bioremediation of hydrocarbons.

Keywords Biofilm; Bioremediation; Pseudomonas; Hydrocarbon; Biosurfactant

\section{Introduction}

The application of microbial bioremediation technology for the removal of oil and its derivatives from contaminated environments has received much attention. The use of plant rhizosphere-inhabiting bacteria in the bioremediation of pollutants in soils has been proposed as an efficient way to spread degrading bacteria in contaminated soils [1]. In most oil contaminated sites some highly toxic derivatives like benzene, toluene, and xylene (BTX) are present [2]. There is considerable interest on adverse health effects and cancer-risk levels for exposures to various BTX compounds. Mehlman [3] reported significant increases in tumors of kidney, liver, and other tissues and organs following exposure to gasoline. Also, common components of gasoline such as benzene, alkyl benzenes and 1,3-butadiene are wellknown carcinogens for both animals and humans [4].

Bioremediation of BTX-contaminated soils and groundwater by indigenous bacteria has received great attention in recent years [5]. One of the approaches to enhance this technology is to use biosurfactants [5] which could increase solubility of oils in water to enhance the bioavailability of the hydrophobic substrates, albeit that expression of metal binding peptides such as siderophores could also enhance bioremediation process as well the role of biofilms. This multicellular aggregates embedded in matricies are found to have applications in bioremediation of hazardous waste sites, waste water treatment and mining acids or metals [6]. Several studies reported that biofilm formation, a surface life style for many bacteria [7], was a promoting factor for biodegradation of Polycyclic Aromatic Hydrocarbons (PAHs) in that biofilm ensured higher bioavailability of PAHs [8], and improved PAHs degradation rate [9]. It is obvious that microbial biofilm formation and production of Extracellular Polymeric Substances (EPS) are generally associated with their metal resistance; tolerance and bioremediation [10], Furthermore, microbial EPS are also of particular interest and relevance to the bioremediation process due to their involvement in flocculation and binding of heavy metals from solutions [11]. There is considerable interest to assess the role of these forming biofilms on monoaromatic compounds biodegradation.

The aim of this work was to assess the capacity of forming biofilms Pseudomonas to synthesize biosurfactants, siderophores and to tolerate high concentrations of hydrocarbons such as gasoline, xylene and benzene to be used as bioremediation agents.

\section{Materials and Methods}

\section{Phenotypic characterization}

Morphological features and biochemical characteristics of the isolates were studied. Colony morphology (shape, color, contour, etc.) was analyzed on $\mathrm{KB}$ after 24 or $48 \mathrm{~h}$ of incubation at $28 \pm 2^{\circ} \mathrm{C}$. Bacterial isolates characterization included Gram staining and biochemical API $20 \mathrm{NE}$ (Biomerieux) multitest. Oxidase was assayed using commercial disks (Sigma Aldrich). Strains were maintained in $\mathrm{LB}$ at $-80^{\circ} \mathrm{C}$ with 50 per cent glycerol. 
Bacterial strains that were employed include a PGPR (plant growthpromoting rhizobacterium) ( $P$. fluorescens (P9) and PGPR $P$. putida (P10), and the strain $P$. aeruginosa (PR) which was isolated from contaminated surface soil. P9 and P10 strains were isolated from Triticum spp. rhizosphere of the region of Mascara (NorthernAlgerian West, $2^{\circ}, 11^{\prime} \mathrm{W}, 35^{\circ}, 26$ 'N).

\section{Siderophore production}

The isolates were assayed for siderophore production on the chrome azurole $S$ agar (CAS) described by Alexander et al. [12] Chrome azurole $S$ agar plates were prepared and spot inoculated with test organism and incubated at $30^{\circ} \mathrm{C}$ for 5 days. Development of yellow orange halo around the colony was considered as positive for siderophore production.

\section{Biosurfactant production kinetics}

The kinetics of biosurfactant production were followed in batch cultures for 96 hours at optimum conditions by measuring the surface tension and emulsification index E24 of supernatant samples obtained after cell separation.

Drop collapsing test: Screening assays for biosurfactants production were done by drop collapsing test, $2 \mu \mathrm{L}$ of mineral oil was added to each well of 96-well microtitre plate and allowed to equilibrate for $1 \mathrm{~h}$ at $37^{\circ} \mathrm{C}$. Then $5 \mu \mathrm{L}$ of culture supernatant was added at the centre of the wells over the oil layer and the shape of the oil drop was examined after $1 \mathrm{~min}$. The supernatant that produced flattened drops was considered as positive for biosurfactant production while those drops that remained intact in round form was considered to be negative for biosurfactant production. The Milli-Q water was used as negative control [13].

Surface tension measurement: The surface tension measurement(s) of cell free supernatant was determined in a tensiometer (Krüss), using the method of [14]. The values reported are the mean of three measurements. All measurements were made on cell-free broth obtained by centrifuging the cultures at $10,000 \mathrm{x}$ g for $25 \mathrm{~min}$.

Emulsification index (E24): The E24 of culture samples was determined by adding $2 \mathrm{ml}$ of gasoline to the same volume of bacterial culture, mixing with a vortex mixer for $2 \mathrm{~min}$, and allowing the mixture to stand for 24 hours. The E24 index is given as percentage of height of emulsified (he) layer ( $\mathrm{mm}$ ) divided by total height of the liquid column (ht) ( $\mathrm{mm}$ ) [15] according to the formula below:

$E 24=(h e / h t) \times 100$

\section{Growth and tolerance to different hydrocarbons}

Overnight cultures were used to inoculate $100 \mathrm{ml}$ sealed bottles containing $5 \mathrm{ml}$ of sterile mineral medium (MM) described by AbuRuwaida et al. [14] medium supplemented with different concentrations ( 5 to $30 \mu \mathrm{l} / \mathrm{ml}$ ) of benzene, xylene and concentrations (50 to $250 \mu \mathrm{l} / \mathrm{ml}$ ) of cyclohexane and gasoline (alcanes, cycloalcanes, d'alcenes and benzene) to different initial $\mathrm{DO}_{600}$. Cultures were incubated at $28 \pm 2^{\circ} \mathrm{C}$ and $300 \mathrm{rpm}$. Growth and tolerance were analyzed by the appearance of turbidity after $24 \mathrm{~h}$ days of cultivation.

\section{Bacterial adhesion to hydrocarbons (BATH) assay}

Microbial surface hydrophobicity was assessed by the Bacterial Adhesion to the Hydrocarbon Method (BATH) described by
Rosenberg et al. [16], with slight modifications. The culture was grown on different carbon sources including gasoline, dodecane and hexadecane. Cells in exponential phase were centrifuged at $7000 \times \mathrm{g}$ for $4 \mathrm{~min}$, washed twice with phosphate urea magnesium buffer (in $\mathrm{gL}^{-1}: \mathrm{K}_{2} \mathrm{HPO}_{4}, \quad 19.7 ; \quad \mathrm{KH}_{2} \mathrm{PO}_{4}, \quad 7.26 ; \mathrm{H}_{2} \mathrm{NCONH}_{2}, \quad 1.8 ; \quad$ and $\left.\mathrm{MgSO}_{4} \cdot 7 \mathrm{H}_{2} \mathrm{O}, 0.2\right)$, and suspended to an $\mathrm{OD}_{600}$ of approximately 1.0 $\left(\mathrm{A} 0\right.$-initial $\left.\mathrm{OD}_{600}\right)$. Next, $500 \mu \mathrm{l}$ of gas oil, hexadecane and dodecane were added to $5 \mathrm{ml}$ of microbial suspension and vortexed for $2 \mathrm{~min}$ at $2500 \mathrm{rpm}$. After $10 \mathrm{~min}$, the $\mathrm{OD}_{600}$ of the aqueous phase was measured $\left(A_{1}\right)$. The degree of hydrophobicity is calculated as $\left[1-\left(A_{0}-A_{1}\right) / A_{0}\right]$ $\times 100 \%$. Each experiment was tested in triplicate. When hydrophobicity is between $0 \%$ and $30 \%$, it is assumed that the cell surface of the microorganism has hydrophilic properties; from $30 \%$ to $40 \%$, the surface has mixed hydrophobic and hydrophilic properties; above $40 \%$, the cell surface of the microorganism has hydrophobic properties [17].

\section{Microtitre plate biofilm formation assay}

Pseudomonas cells were harvested by centrifugation (9000 g, 10 min), washed twice with sterile water, and then resuspended in phosphate-buffered saline (PBS) to a $\mathrm{DO}_{580} \mathrm{~nm}$ of $0,4\left(\sim 2.10^{8}\right.$ bacteria $\left.\mathrm{ml}^{-1}\right)$. Cultures were transferred to standing culture vessels. Polystyrene 96-well microtitre plates were filled with $100 \mu \mathrm{L}$ of culture per well. The cultures were allowed to stand at $28^{\circ} \mathrm{C}$ and $37^{\circ} \mathrm{C} / 24 \mathrm{~h}$ for the specified times. The microtitre plate wells were gently washed three times with $150 \mu \mathrm{L}$ of sterile water to remove loosely associated bacteria. After the incubation period, cultures were removed, and dried at $30^{\circ} \mathrm{C}$ for $30 \mathrm{~min}$. Samples were stained by the addition of the $1 \%$ crystal violet solution $(100 \mu \mathrm{l})$ to each well above the initial inoculation level and incubated for $30 \mathrm{~min}$. The vessels were then washed three times with $150 \mu \mathrm{L}$ of sterile water. The intensity of crystal violet staining was measured. The samples were incubated for $6 \mathrm{~h}$, after which the $\mathrm{OD}_{590}$ values were measured on an ELISA plate reader. All the samples were prepared in triplicate for each sampling time with a negative control containing no cells. The amount of surface-attached biofilm was determined by using a modified crystal violet method [18]. Isolates were classified as biofilm producers if $\mathrm{OD}_{590}$ was $>0.200$ and further classified as strong, moderate, weak, or zero biofilm formers based on their final $\mathrm{OD}_{590}$ reading [19].

\section{Statistical Analysis}

The correlation between biofilm formation, surface tension and emulsification index E24 was carried out using Pearson's correlation with STATISTICA 7.0 software version. At least three replicates were used in each assay.

\section{Results and Discussion}

\section{Characterization of Pseudomonas strains}

Selected strains showed different colony morphology in KB plates: Pseudomonas colonies were mucoid, wet, and convex. Both strains were Gram negative rods, oxidase and catalase positive, nitrate reductase, Indol, b-glucosidase, Gelatin hydrolase and arginine hydrolase positive. They were able to grow using several carbohydrates and organic acids like glucose, mannose, mannitol, gluconate, capric acid, malic acid, citrate, phenylacetic acid, octanoate and citrate as sole carbon sources. 
As described in Bergy's Manual of Determinative Bacteriology the phenotypic tests showed that these strains belong to $P$. fluorescens (P9), $P$. putida (P10) and $P$. aeruginosa (PR). The $P$. putida group has been extensively used in xenobiotic bioremediation and it includes the first patented bioremediation agent, registered in 1974 [20].

\section{Surfactant production}

Surfactant production was assessed by the drop collapsing test, the determination of Surface Tension (ST) reduction and emulsification activity (E24). In the drop collapsing test a flat drop was observed around the colonies, which indicates a biosurfactant activity. As shown in Figure 1, all the isolates were able to lower the surface tension, presumably via biosurfactant production. We observed the reduction of surface tension values from $75 \mathrm{mN} / \mathrm{m}$ to $55 \mathrm{mN} / \mathrm{m}, 45 \mathrm{mN} / \mathrm{m}$ and 36 $\mathrm{mN} / \mathrm{m}$, respectively for $P$. aeruginosa, $P$. fluorescens and $P$. putida. Nitschke et al. [21] reported that glycolipids produced by Pseudomonas are low molecular weight compounds, which can lower the medium surface tension below $30 \mathrm{mN} / \mathrm{m}$. It can be assumed that this will help to improve the accessibility and bioavailability of waterimmiscible petroleum.

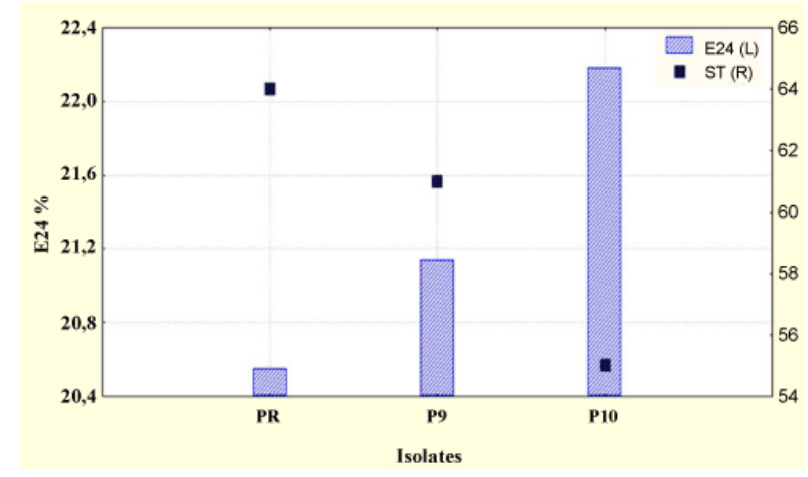

Figure 1: Emulsification Index and surface tension evolution of Culture supernatant.

E24 was the method used to quantify the emulsification caused by the biosurfactants produced by the tested bacteria. All strains presented varying degrees of emulsification, indicating the production of biosurfactant compounds. The $P$. aeruginosa strain showed the best result, reaching an emulsification index of $27.94 \%$. This value is in agreement with previous results. For example, Pruthi et al. [22] values found that cultures of $P$. aeruginosa growing on a similar medium presented an emulsification index value of $30 \%$, and was considered an excellent producer of biosurfactant. While surface tension reduction enhances oil-water miscibility and solid oil removal, stable oil-water emulsions helps in dispersion of roplets of one immiscible liquid within another and enhance availability [23]. Chakraborty et al. [24] reported that the microbial cell surface is an important factor governing growth and their adhesion on non-aqueous phase liquids.

According to Ron et al. [25] several Pseudomonas are able to synthesize biosurfactants of diverse chemical nature. The most studied of these compounds are the rhamnolipids produced by $P$. aeruginosa. Microbial compounds that exhibit particularly high surface activity and emulsifying activity are classified as biosurfactants. These are structurally diverse surface active compounds capable of reducing surface and interfacial tension at the interfaces between liquids, solids, and gases, thereby allowing them to mix or disperse readily as emulsions in water or other liquids [26]. Interestingly, Al-Tahhan et al. [27] demonstrated that rhamnolipids caused the release of lipopolysaccharide (LPS) from the outer membrane and resulted in an increase in the cell surface hydrophobicity. These findings are consistent with other reports and corroborated the presence of tenso active compounds secreted by these fluorescents isolated strains.

\section{Use of hydrocarbon as a carbon and energy source}

Growth in complex hydrocarbon mixtures such as gasoline as sole carbon source was tested by appearance of turbidity after $24 \mathrm{~h}$. They showed a moderate tolerance for all some source of carbon, for gasoline degradation the bacterial consortia and $P$. aeruginosa seemed to tolerate more this mixture hydrocarbon as described in figure $2 \mathrm{~d}$, whereas $P$. fluorescens and P. putida were more sensitive.

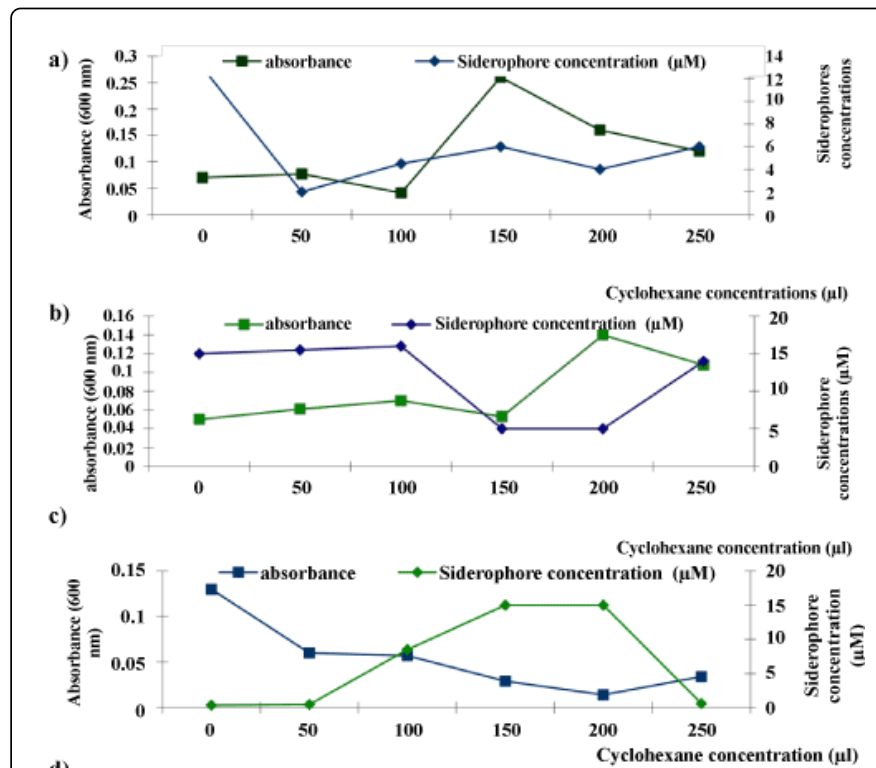

d)

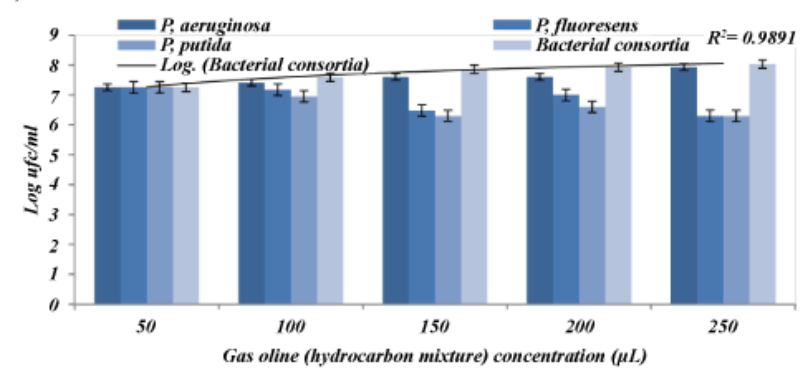

Figure 2: The bacterial growth curves in the presence of cyclohexane a.b.c and gasolined.

Gasoline is a complex mixture of volatile hydrocarbons, predominantly in the $\mathrm{C} 4-\mathrm{C} 12$ range, with a boiling range of $50-200{ }^{\circ} \mathrm{C}$ with a typical composition (\% volume) of 4-8\% alkanes; $2-5 \%$; alkenes; $25-40 \%$ isoalkanes; $3-7 \%$ cycloalkanes; $1-4 \%$ cycloalkenes; and $20-50 \%$ total aromatics (0.5-2.5\% benzene) [28]. Ridgway et al. [29] showed that $87 \%$ of the nearly 300 strains of gasoline-degrading bacteria isolated from a contaminated aquifer were Pseudomonas spp. Our study has also shown that no exponential growth was detected for cyclohexane as carbon source (Figure 2a-2c). These findings suggest 
that the aromatic hydrocarbon compounds could support cell growth more than the cyclic one like the cyclohexane. These data are consistent with other report of Di Martino [2] focused on the Naphthalene and cyclohexane degradation, no growth was detected in these carbon sources.

In accordance, Benzene and xylene were selected as representatives of monoaromatic compounds. Interestingly, the tested strains were able to grow with these carbon sources but with some fluctuations. $P$. fluorescens (P9) showed the best performance in the monoaromatic hydrocarbons tested, with capability to tolerate more xylene at concentrations up to $20 \mu \mathrm{l} / \mathrm{ml}$ and to tolerate high concentrations of benzene, however $P$. putida was able to grow on xylene as a carbon source but not on benzene because it lacks enzyme machinery for catabolism of benzene (Figure 3). Taken together, our data are consistent with Lee et al. [30] data. In contrast to other results, we signaled a decrease in the growth of $P$. aeruginosa (PR) for xylene and benzene as a carbon source. From the results described above, it seems possible, that this implies the implication of the tod -tol pathway for BTX compounds, which can be active or not. The individual compounds constituting BTX mixtures are reported to be easily degraded by the microorganisms of soil and surface water. Catabolic degradation of BTX via two typical pathways (the tod and the tol pathways) has been extensively studied [31]. Lee et al. [30] reported that two metabolic barriers prevent the complete mineralization of BTX mixtures and have been known to be imposed on the tod and the tol pathways: 3,6-dimethylcatechol produced from p-xylene cannot be metabolized further in the tod pathway, and benzene cannot be assimilated in the tol pathway. As was recently pointed out by Shim et al. [32], $P$. putida and $P$. fluorescens could effectively degrade benzene and xylene.

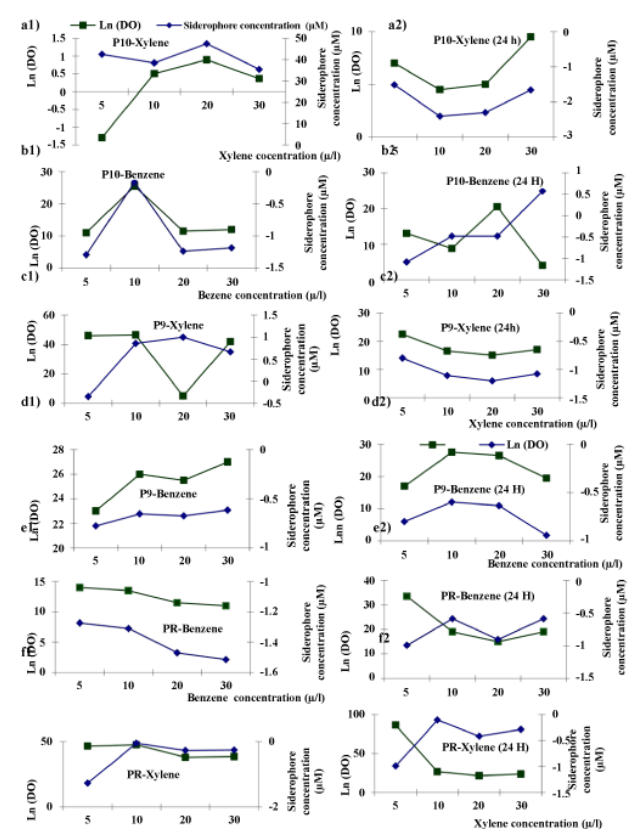

Figure 3: The bacterial growth curves and siderophores rates in the presence of xylene and benzene.

In each culture the behavior of carbon source consumption was related to the growth curve of the cultures and the amount of siderophores. As described in Figure 3, the degradation of benzene and xylene are in parallel of the amount of siderophores released in cultures supernatant with the exception of $\mathrm{P} 10$ for the use of benzene after $24 \mathrm{~h}$. These experiments carried out have proven that the siderophore content increasing or decreasing along with the biomass concentration, from the early exponential growth phase until the decline one. Nevertheless, xylene produced more siderophores than benzene did. Siderophores production in $P$. fluorescens seems to be influenced by different carbon sources [33]. The concurrent increase in both concentrations is consistent with previous studies that found that siderophores production in Pseudomonas is influenced by the carbon source.

\section{Microbial adhesion to hydrocarbon}

The results showed that each strain had significantly different Cell Surface Hydrophobicity (CSH) in comparison with the other strain as is noticeable in figure 4 . The tested strain $P$. aeruginosa had more hydrophobic properties $(49.62 \%)$ than $P$. fluorescens $(22.9 \%)$ and $P$. putida (17.7\%). However, during growth in other hydrocarbon sources such as hexadecane and dodecane, different behavior was observed where the hydrophobicity of bacteria decreases and reaches $4.1 \%$ for dodecane. As expected, the results differed when the strain was kept in different carbon sources, according to Chakraborty et al. [24], the microbial cell surface is an important factor governing growth and their adhesion on non-aqueous phase liquids. What is more, this factor can also be influenced by the addition of surfactants, which on the one hand can enhance bioavailability of hydrocarbons, but on the other hand change the cell surface hydrophobicity [34].

Bacterial adhesion is one of the first steps of a biofilm formation which is discussed in the subsequent lines, Cell Surface Hydrophobicity (CSH) has been considered as an important factor in the stability of microbial aggregates [35]. According to Li et al. [36], extracellular polymeric substances play a significant role in bacterial aggregation. Bos et al. [37] noted that hydrophobic strains adhere better to hydrophobic substrate, while hydrophilic strains have a thermodynamic preference for hydrophilic substrata. These findings are consistent with previous reports indicating that the best biodegradation of hydrocarbons was observed when cells had hydrophilic-hydrophobic properties ((hydrophobicity was approximately $30 \%$ ). This may imply that anionic surfactants show marked biological activity either by binding to various bioactive macromolecules [38].

\section{Biofilms formation}

All Strains were found to produce a greasy-looking biofilm which varied in thickness from an 'almost invisible film' to a paper-thick structure depending on the presence of xylene or benzene. Their morphological characteristics after $48 \mathrm{~h}$ of cultivation were like a thin pellicle, particularly in the presence of xylene ((Figure $5 b)$. The results, developed in this study, showed that our isolates exhibited an important biofilm mass, the P. fluorescens and P. aeruginosa exhibited increased biofilm formation. The Pseudomonas isolates had OD590 readings ranging from 0.29 to 0.35 (Figure 5a), according to Stepanović et al. [19] and Perez et al. [39] classification, these isolates were categorized as having moderate biofilm adherence properties, despite they were categorized as slime-producers and exhibited a coordinated multicellular behavior called swarming with a crystal structure of the EPS matrixe (Figure 5c). Microbial EPS is crucial to the formation of biofilm and cell aggregates, which contribute to 
protect cells from hostile environments and can bind significant amounts of heavy metals. In contrast to the archetypal S-L interface biofilms, bacterial biofilms also form at the air liquid (A-L) interface of static liquids and are sometimes referred to as 'pellicles' [40]. Forming biofilms by these strains is considered a natural strategy to maintain a favorable niche in stressful environments with increased hydrocarbon concentrations. Statistically no significant positive correlation $(\mathrm{r}=$ 0.94; $\mathrm{p}>0.01$ ) between biofilm formation and surface tension (Figure 6), whereas with E24 and cells hydrophobicity we signaled a linear negative relationship $(\mathrm{r}=-93, \mathrm{r}=-086)$.

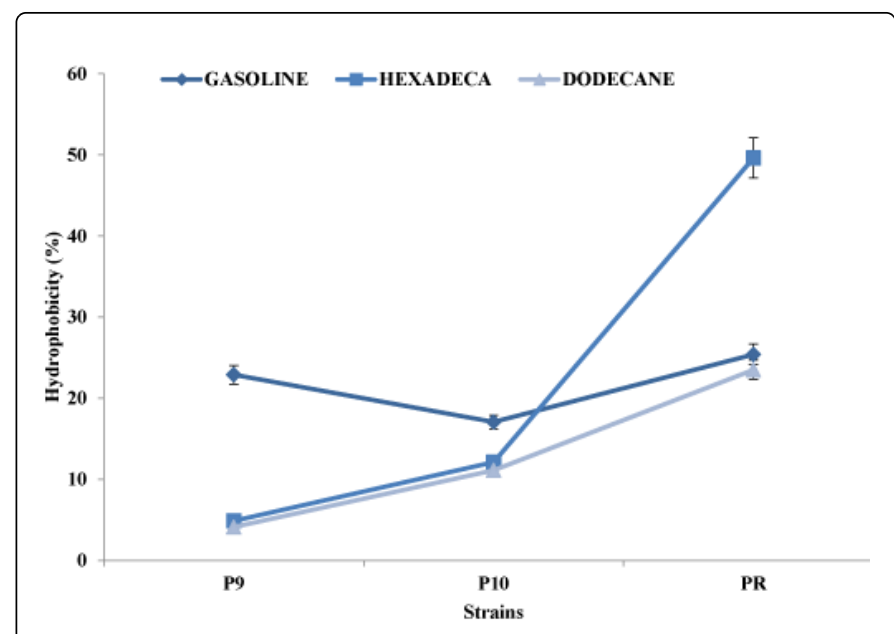

Figure 4: Cell hydrophobicity.

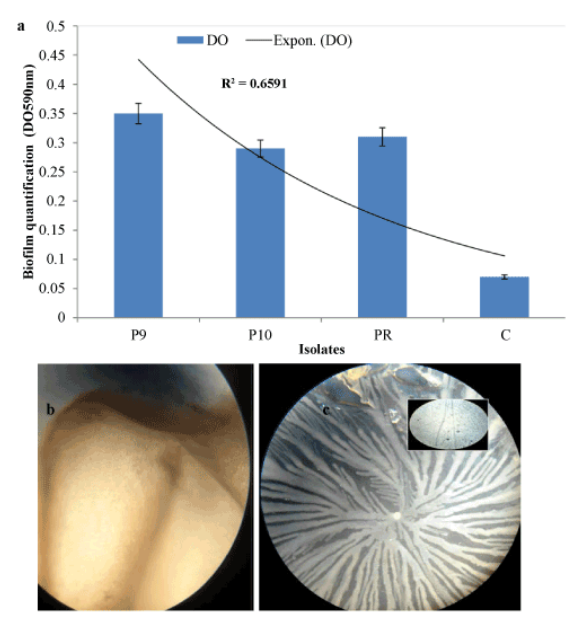

Figure 5: Biofilm and pellicule formation by hydrocarbon degrading bacteria, the crystal structure of the EPS matrixe with $40 \times$ magnification in light microscope.

Even though the correlations obtained in the present study are not statistically significant, this disparity can be attributed to release of different concentrations of lipopolysaccharides released from the cell surface. Thus biosurfactants alters the cell-to-cell and cell-to-surface interactions and determines the attachment of microorganisms on this kind of niche. Results obtained in the present study indicate that increase in cells hydrophobicity does not necessarily enhances the attachment of viable cells (biofilm) on the surface or lead to stronger biofillms, since this hydrophobicity is influenced by many factors.

The results described above coincides with the previous literature report, which discusses the requirement of exo polysaccharides in maintaining the structure and function of biofilm formed by certain species of Pseudomonas on abiotic surfaces as was reported by Danese et al. [41].

In actual studies most attention has focused on biofilms formed at solid-liquid (S-L) interfaces, but also to biofilms formed on interface between air and liquid (A-L interface) [42]. According to Koza et al. [43] Pseudomonads are able to form a variety of biofilms that colonize the air-liquid (A-L) interface of static liquid microcosms, and differ in matrix composition, strength, resilience and degrees of attachment to the microcosm walls. They are also well known for their ability of resistance to toxic molecules, including antibiotics, heavy metals, detergents, and organic solvents [44]. Interestingly, in this study we signaled the bacterial adaptation through the rapid colonisation of the air-liquid interface by the production of EPS in such as carbon sources.

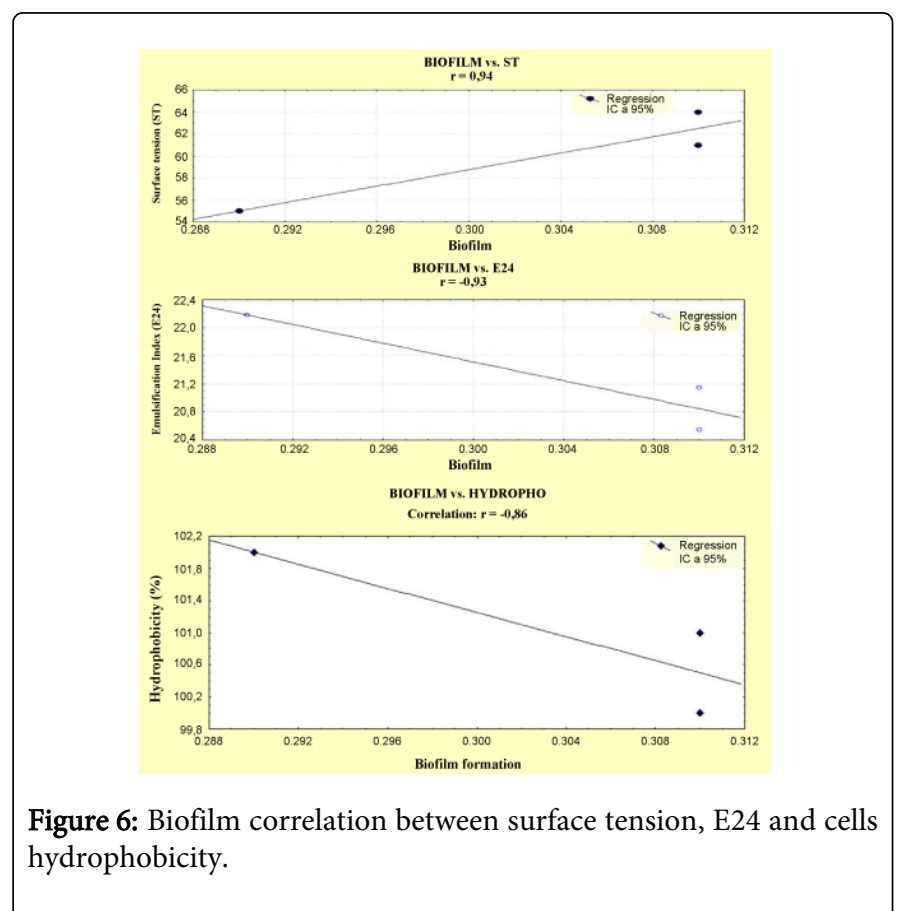

\section{Conclusion}

This article offers important insights into the biodegradation of monoaromatic and cyclic hydrocarbons compounds. In our study, the three selected strains were producing biosurfactants, siderophores, exopolisaccharides and presented desirable high tolerance characteristics to different hydrocarbons when incubated with different carbon source. Furthermore, the results achieved up indicate that the biofilm is able to grow more in the presence of xylene and thereby maintain itself over a long period of incubation with different aspects of thickness. This research will be useful in developing an important technique that may lead to improved bioremediation rationales and approaches. These strains might be promising candidates for bioremediation of hydrocarbon -contaminated soils. 


\section{Acknowledgements}

The research was supported by the national research project (PNR project) of the Direction for Research Programming, Evaluation and Prospective Study (DGRSDT), Government of Algeria. The anonymous reviewers are sincerely thanked for their beneficial suggestions to improve the manuscript.

\section{References}

1. Andersen SM, Jorgensen C, Jacobsen CS (2001) Development and utilisation of a medium to isolate phenanthrene-degrading Pseudomonas spp. Appl Microbiol Biot 55: 112-116.

2. Di Martino C, López NI, Raiger Iustman LJ (2012) Isolation and characterization of benzene, toluene and xylene degrading Pseudomonas sp. selected as candidates for bioremediation. Int Biodeter Biodegr 67: 15-20.

3. Mehlman MA (1992) Dangerous and cancer-causing properties of products and chemicals in the oil refining and petrochemical industry. VIII. Health effects of motor fuels: carcinogenicity of gasoline--scientific update. Environ Res 59: 238-249.

4. Jean JS, Lee MK, Wang SM, Chattopadhyay P, Maity JP (2008) Effects of inorganic nutrient levels on the biodegradation of benzene, toluene, and xylene (BTX) by Pseudomonas spp. in a laboratory porous media sand aquifer model. Bioresour Technol 99: 7807-7815.

5. Rahman KS, Rahman TJ, Kourkoutas Y, Petsas I, Marchant R, et al. (2003) Enhanced bioremediation of n-alkane in petroleum sludge using bacterial consortium amended with rhamnolipid and micronutrients. Bioresour Technol 90: 159-168.

6. Singh R, Paul D, Jain RK (2006) Biofilms: implications in bioremediation Trends Microbiol 14: 389-397.

7. Watnick P, Kolter R (2000) Biofilm, city of microbes. J Bacteriol 182: 2675-2679.

8. Johnsen AR, Karlson U (2004) Evaluation of bacterial strategies to promote the bioavailability of polycyclic aromatic hydrocarbons. Appl Microbiol Biotechnol 63: 452-459.

9. Leglize P, Alain S, Jacques B, Corinne L (2008) Adsorption of phenanthrene on activated carbon increases mineralization rate by specific bacteria. J Hazard Mater 151: 339-347.

10. Pal A, Paul AK (2008) Microbial extracellular polymeric substances: central elements in heavy metal bioremediation. Indian J Microbiol 48: 49-64.

11. Chien CC, Lin BC, Wu CH (2013) Biofilm formation and heavy metal resistance by an environmental Pseudomonas sp. Biochem Eng J 78 132-137.

12. Alexander DB, Zuberer DA (1991) Use of chrome azurol S reagents to evaluate siderophore production by rhizosphere bacteria. Biol Fert Soils 12: $39-45$.

13. Sriram MI, Kalishwaralal K, Deepak V, Gracerosepat R, Srisakthi K, et al. (2011) Biofilm inhibition and antimicrobial action of lipopeptide biosurfactant produced by heavy metal tolerant strain Bacillus cereus NK1. Colloids Surf B Biointerfaces 85: 174-181.

14. Abu-Ruwaida AS, Banat IM, Haditirto S, Salem A, Kadri M (1991) Isolation of biosurfactant-producing bacteria, product characterization, and evaluation. Acta Biotechnol 11: 315-324.

15. Cooper DG, Goldenberg BG (1987) Surface-Active Agents from Two Bacillus Species. Appl Environ Microbiol 53: 224-229.

16. Rosenberg M, Gutnick D, Rosenberg E (1980) Adherence of bacteria to hydrocarbons: A simple method for measuring cell-surface hydrophobicity. FEMS Microbiol Lett 9: 29-33.

17. Kaczorek E, Olszanowski A (2011) Uptake of Hydrocarbon by Pseudomonas fluorescens (P1) and Pseudomonas putida (K1) Strains in the Presence of Surfactants: A Cell Surface Modification. Water Air Soil Pollut 214: 451-459.
18. O'Toole GA, Kolter R (1998) Initiation of biofilm formation in Pseudomonas fluorescens WCS365 proceeds via multiple, convergent signalling pathways: a genetic analysis. Mol Microbiol 28: 449-461.

19. Stepanović S, Vuković D, Dakić I, Savić B, Švabić-Vlahović M (2000) A modified microtiter-plate test for quantification of staphylococcal biofilm formation. J Microbiol Meth 40: 175-179.

20. Prescott LM, Harley JP, Klein DA (2002) Microbiology. 5edn McGrawHill, New York 1015.

21. Nitschke M, Costa SG, Haddad R, Gonçalves LA, Eberlin MN, et al. (2005) Oil wastes as unconventional substrates for rhamnolipid biosurfactant production by Pseudomonas aeruginosa LBI. Biotechnol Prog 21: 562-566.

22. Pruthi V, Cameotra SS (1995) Rapid method for monitoring maximum biosurfactant production obtained by acetone precipitation. Biotechnol Tech 9: 271-276.

23. Shete AM, Wadhawa G, Banat IM, Chopade BA (2006) Mapping of patents on bioemulsifier and biosurfactant: A review. J Sci Ind Res India 65: 91-115.

24. Chakraborty S, Mukherji S, Mukherji S (2010) Surface hydrophobicity of petroleum hydrocarbon degrading Burkholderia strains and their interactions with NAPLs and surfaces. Colloids Surf B Biointerfaces 78: 101-108.

25. Ron EZ, Rosenberg E (2002) Biosurfactants and oil bioremediation. Curr Opin Biotechnol 13: 249-252.

26. Singh P, Cameotra SS (2004) Enhancement of metal bioremediation by use of microbial surfactants. Biochem Bioph Res Co 319: 291-297.

27. Al-Tahhan RA, Sandrin TR, Bodour AA, Maier RM (2000) Rhamnolipidinduced removal of lipopolysaccharide from Pseudomonas aeruginosa: effect on cell surface properties and interaction with hydrophobic substrates. Appl Environ Microbiol 66: 3262-3268.

28. International Agency for Research on Cancer (1989) IARC monographs on the evaluation of carcinogenic risks to humans / World Health Organization, International Agency for Research on Cancer.

29. Ridgway HF, Safarik J, Phipps D, Carl P, Clark D (1990) Identification and catabolic activity of well-derived gasoline-degrading bacteria from a contaminated aquifer. Appl Environ Microbiol 56: 3565-3575.

30. Lee JY, Jung KH, Choi SH, Kim HS (1995) Combination of the tod and the tol pathways in redesigning a metabolic route of Pseudomonas putida for the mineralization of a benzene, toluene, and p-xylene mixture. Appl Environ Microbiol 61: 2211-2217.

31. Harayama S, Leppik RA, Rekik M, Mermod N, Lehrbach PR, et al. (1986) Gene order of the TOL catabolic plasmid upper pathway operon and oxidation of both toluene and benzyl alcohol by the xylA product. J Bacteriol 455-461.

32. Shim H, Hwang B, Lee SS, Kong SH (2005) Kinetics of BTEX biodegradation by a coculture of Pseudomonas putida and Pseudomonas fluorescens under hypoxic conditions. Biodegradation 16: 319-327.

33. Meyer JM, Abdallah MA (1978) The Fluorescent Pigment of Pseudomonas fluorescens: Biosynthesis, Purification and Physicochemical Properties. Microbiology 107: 319-328.

34. Zeng G, Liu Z, Zhong H, Li J, Yuan X, et al. (2011) Effect of monorhamnolipid on the degradation of $n$-hexadecane by Candida tropicalis and the association with cell surface properties. Appl Microbiol Biotechnol 90: 1155-1161.

35. Liu Y, Yang SF, Li Y, Xu H, Qin L, et al. (2004) The influence of cell and substratum surface hydrophobicities on microbial attachment. J Biotechnol 110: 251-256.

36. Li ZH, Kuba T, Kusuda T (2006) The influence of starvation phase on the properties and the development of aerobic granules. Enzyme Microb Tech 38: 670-674.

37. Bos R, van der Mei HC, Busscher HJ (1999) Physico-chemistry of initial microbial adhesive interactions - its mechanisms and methods for study. FEMS Microbiol Rev 23: 179-230.

38. Cserháti T, Forgács E, Oros G (2002) Biological activity and environmental impact of anionic surfactants. Environ Int 28: 337-348. 
Citation: Meliani A, Bensoltane A (2014) Enhancement of Hydrocarbons Degradation by Use of Pseudomonas Biosurfactants and Biofilms. J Pet Environ Biotechnol 5: 168. doi:10.4172/2157-7463.1000168

Page 7 of 7

39. Perez LRR, Costa MCN, Freitas ALP, Barth AL (2011) Evaluation of biofilm production by Pseudomonas Aeruginosa isolates recovered from cystic fibrosis and non-cystic fibrosis patients. Braz J Microbiol 42: 476-479.

40. Branda SS, Vik S, Friedman L, Kolter R (2005) Biofilms: the matrix revisited. Trends Microbiol 13: 20-26.

41. Danese PN, Pratt LA, Kolter R (2000) Exopolysaccharide production is required for development of Escherichia coli K-12 biofilm architecture. J Bacteriol 182: 3593-3596.
42. Constantin OE (2009) Bacterial Biofilms Formation at Air Liquid Interfaces. Innovative Romanian Food Biotechnology 5: 18-22.

43. Koza A, Hallett PD, Moon CD, Spiers AJ (2009) Characterization of a novel air-liquid interface biofilm of Pseudomonas fluorescens SBW25. Microbiology 155: 1397-1406.

44. Viti C, Decorosi F, Mini A, Tatti E, Giovannetti L (2009) Involvement of the oscA gene in the sulphur starvation response and in $\mathrm{Cr}(\mathrm{VI})$ resistance in Pseudomonas corrugata 28. Microbiology 155: 95-105. 